\title{
Physical activity assessment with accelerometers: an evaluation against doubly labeled water
}

Citation for published version (APA):

Plasqui, G., \& Westerterp, K. R. (2007). Physical activity assessment with accelerometers: an evaluation against doubly labeled water. Obesity, 15(10), 2371-2379. https://doi.org/10.1038/oby.2007.281

Document status and date:

Published: 01/01/2007

DOI:

10.1038/oby.2007.281

Document Version:

Publisher's PDF, also known as Version of record

Document license:

Taverne

Please check the document version of this publication:

- A submitted manuscript is the version of the article upon submission and before peer-review. There can be important differences between the submitted version and the official published version of record.

People interested in the research are advised to contact the author for the final version of the publication, or visit the DOI to the publisher's website.

- The final author version and the galley proof are versions of the publication after peer review.

- The final published version features the final layout of the paper including the volume, issue and page numbers.

Link to publication

\footnotetext{
General rights rights.

- You may freely distribute the URL identifying the publication in the public portal. please follow below link for the End User Agreement:

www.umlib.nl/taverne-license

Take down policy

If you believe that this document breaches copyright please contact us at:

repository@maastrichtuniversity.nl

providing details and we will investigate your claim.
}

Copyright and moral rights for the publications made accessible in the public portal are retained by the authors and/or other copyright owners and it is a condition of accessing publications that users recognise and abide by the legal requirements associated with these

- Users may download and print one copy of any publication from the public portal for the purpose of private study or research.

- You may not further distribute the material or use it for any profit-making activity or commercial gain

If the publication is distributed under the terms of Article $25 \mathrm{fa}$ of the Dutch Copyright Act, indicated by the "Taverne" license above, 


\title{
Physical Activity Assessment With Accelerometers: An Evaluation Against Doubly Labeled Water
}

\author{
Guy Plasqui,* and Klaas R. Westerterp $\dagger$
}

\begin{abstract}
PLASQUI, GUY, AND KLAAS R. WESTERTERP. Physical activity assessment with accelerometers: an evaluation against doubly labeled water. Obesity. 2007;15: 2371-2379.

This review focuses on the ability of different accelerometers to assess daily physical activity as compared with the doubly labeled water (DLW) technique, which is considered the gold standard for measuring energy expenditure under free-living conditions. The PubMed Central database (U.S. $\mathrm{NIH}$ free digital archive of biomedical and life sciences journal literature) was searched using the following key words: doubly or double labeled or labeled water in combination with accelerometer, accelerometry, motion sensor, or activity monitor. In total, 41 articles were identified, and screening the articles' references resulted in one extra article. Of these, 28 contained sufficient and new data. Eight different accelerometers were identified: 3 uniaxial (the Lifecorder, the Caltrac, and the CSA/MTI/Actigraph), one biaxial (the Actiwatch AW16), 2 triaxial (the Tritrac-R3D and the Tracmor), one device based on two position sensors and two motion sensors (ActiReg), and the foot-ground contact pedometer. Many studies showed poor results. Only a few mentioned partial correlations for accelerometer counts or the increase in $\mathrm{R}^{2}$ caused by the accelerometer. The correlation between the two methods was often driven by subject characteristics such as body weight. In addition, standard errors or limits of agreement were often large or not presented. The CSA/MTI/Actigraph and the Tracmor
\end{abstract}

Received for review April 12, 2006.

Accepted in final form February 26, 2007.

The costs of publication of this article were defrayed, in part, by the payment of page charges. This article must, therefore, be hereby marked "advertisement" in accordance with 18 U.S.C. Section 1734 solely to indicate this fact.

*Department of Biomedical Science, University of Wollongong, Wollongong, Australia; and $\nmid$ Department of Human Biology, Maastricht University, Maastricht, The Netherlands. Address correspondence to Klaas R. Westerterp, Department of Human Biology, University of Maastricht, PO Box 616, 6200MD Maastricht, The Netherlands.

E-mail: k.westerterp@hb.unimaas.nl

Copyright (C) 2007 NAASO were the two most extensively validated accelerometers. The best results were found for the Tracmor; however, this accelerometer is not yet commercially available. Of those commercially available, only the CSA/MTI/Actigraph has been proven to correlate reasonably with DLW-derived energy expenditure.

Key words: physical activity, calorimetry, isotope, energy expenditure

\section{Introduction}

A sedentary lifestyle, often adopted during adolescence and continued in adulthood, is a major concern for public health. Whereas at the age of nine, $97 \%$ of children of a European population meet the activity recommendations, only $82 \%$ of the boys and $62 \%$ of the girls meet these recommendations at the age of 15 (1). Individuals who are regularly physically active enjoy better health and have a greater degree of independence than those who are sedentary (2). Low levels of physical activity are associated with several diseases, such as cardiovascular disease $(3,4)$, diabetes mellitus type II $(5-8)$, osteoporosis $(9,10)$, obesity (11-13), and some cancers such as colon or breast cancer (14). The dramatic increase in the prevalence of overweight and obesity over the past decades (15-17) is related to, and often ascribed to, lower levels of physical activity (13).

Physical activity $(\mathrm{PA})^{1}$ can be defined as body movement, produced by skeletal muscles, resulting in energy expenditure (18). It is a complex behavior, including sports as well as non-sports activities. Sports are often planned, structured, and repetitive, with the objective of improving or maintaining physical fitness (18), whereas non-sports activities can be subdivided into different categories such as occupational, leisure-time, and household activities but also

\footnotetext{
${ }^{1}$ Nonstandard abbreviations: PA, physical activity; DLW, doubly labeled water; PAL, PA level; TEE, total energy expenditure; BMR, basal metabolic rate; SMR, sleeping metabolic rate; AEE, activity-related energy expenditure; EE, energy expenditure; $\mathrm{BM}$, body mass; FFM, fat free mass; FM, fat mass; RMR, resting metabolic rate.
} 
personal care and transportation. From this definition, it is clear that PA has an impact on energy expenditure, and the extent to which body movement leads to energy expenditure is dependent on body size and body composition.

The complex nature of PA makes it difficult to accurately measure all of its aspects and assess the impact on outcome parameters, such as energy expenditure. Different measuring techniques available can be grouped into five categories: behavioral observation, self-report (questionnaires and activity diaries), physiological markers (heart rate, body temperature, ventilation), motion sensors (pedometers, accelerometers), and indirect calorimetry (19-21). Ideally, PA should be assessed during daily life, over periods long enough to be representative of the habitual activity level and with minimal discomfort to the subject. Furthermore, it is important to identify PA patterns (frequency, duration, intensity) as well as activity-related energy expenditure.

This review will focus on the ability of different accelerometers to assess daily PA as compared with the doubly labeled water (DLW) technique, which is considered the gold standard for measuring energy expenditure under freeliving conditions.

\section{Activity-related Energy Expenditure and the PA Level $(\boldsymbol{P A L})$}

By combining a measurement of total energy expenditure (TEE) by means of DLW with basal metabolic rate (BMR) by a ventilated hood [or sleeping metabolic rate (SMR)with a respiration chamber], activity-related energy expenditure (AEE) can be calculated as: $\mathrm{AEE}=(0.9 \times \mathrm{TEE})-\mathrm{BMR}$. This calculation assumes diet-induced thermogenesis to be $10 \%$ of TEE. Another common way to convert energy expenditure to the PAL is the expression of TEE as a multiple of BMR, PAL $=$ TEE $\times \mathrm{BMR}^{-1}$.

Since the DLW technique is expensive, this method is used most often in small study populations. Furthermore, this technique provides an accurate measure of TEE, but no information on PA patterns in terms of frequency, duration, and intensity is available. It is, however, the only method available to accurately measure TEE under free-living conditions and is, therefore, considered to be the gold standard for the measurement of energy expenditure (EE) during daily life.

\section{Accelerometry}

Motion sensors are probably the oldest tools available to measure body movement or PA. They have evolved from mechanical pedometers to electronic uniaxial and triaxial accelerometers. The first pedometer was probably invented by Leonardo da Vinci, $~ 500$ years ago (22). It was designed to count steps by responding to vertical acceleration, moving a lever arm up and down, resulting in rotation of a gear. Another mechanical motion sensor, the actometer, was developed by Schulman and Reisman (23). They used a mod- ified wristwatch to transform vertical accelerations into rotation of an internal rotor. Movement of the rotor is then registered as a change in position of the clock hands, and the resulting change in time displayed is used as the activity measure (24). In the 1970s, the electronic large-scale integrated motor activity monitor was developed (25). The device is slightly larger than a wristwatch and can be worn at various body locations. The sensor consists of a cylinder containing a ball of mercury. Tilting of the instrument causes the ball of mercury to roll down the cylinder, making contact with a mercury switch at the end of the cylinder. The number of closures of the mercury switch is recorded and used as a measure of PA (25).

Currently, several electronic pedometers are commercially available (26). Pedometers can be used to count steps and, when the step length is known, walking distance and thus provide information about total walking and/or running activity. Since only the total amount of steps is monitored, there is no information on frequency, duration, and intensity of PA (27). Because of the complex nature of different activities in daily life, the applicability of pedometers to assess free-living activity is limited.

Accelerometers are electronic motion sensors that consist of piezo-resistive or piezo-electric sensors. Piezo-resistive accelerometers respond to accelerations by a change in resistance of silicon resistors, which is then transformed to a voltage proportional to the amplitude and frequency of the acceleration of the small mass in the sensor. Piezo-resistive accelerometers require an external power source and also respond to a constant acceleration such as gravity (28). Piezo-electric accelerometers generate an electric charge in response to a mechanical force, thus, acceleration (28). They do not respond to constant acceleration, and their major advantage is that no power supply is required, except for data storage, resulting in a considerable reduction in size and weight of the device.

Over the past decades, advances in technology have resulted in the development of small and light instruments that are able to collect data at a high-frequency and store minuteby-minute data over several days or weeks. Uniaxial accelerometers measure accelerations in one direction, usually in the vertical plane, whereas triaxial accelerometers measure accelerations in the anteroposterior, mediolateral, and vertical direction. With the wide range of activities a subject can perform, triaxial accelerometers provide more information and show a better relationship to AEE than uniaxial (29).

Ideally, an accelerometer should be small, light, unobtrusive, sensitive within the right frequencies and amplitudes, and able to store data over long periods of time. The size of the device is important in order not to interfere with normal daily activity patterns. Bouten et al. have summarized the frequency and amplitude range required to accurately measure human movement (28). For accelerometers placed at 
waist level, a frequency band between 0.3 and $3.5 \mathrm{~Hz}$ and an amplitude range of $-6 \mathrm{~g}$ to $6 \mathrm{~g}$ should suffice to capture daily PA. Within these ranges, accelerations during lowintensity activities, such as sedentary activities or walking, as well as high-intensity activities or exercise, such as running and jumping, can be measured (28). Low- and high-pass filters can be used to eliminate those frequencies that are unlikely to arise from human movement, such as high frequencies due to transportation.

To test the capability of accelerometers to predict EE, validation against indirect calorimetry is necessary. Many accelerometers have been tested under laboratory conditions during standardized activities (29-34), in field settings against portable calorimeters $(35,36)$, or in the controlled environment of a whole room calorimeter (37-39). Most accelerometers show good to very good correlations $(\mathrm{r}=$ 0.74 to 0.95 ) with $\mathrm{EE}$ during walking and running on a treadmill or with other defined activities (29,31-34). An increasing number of accelerometers have also been validated against DLW under unconfined conditions in daily life. The purpose of this review is to compare the ability of the different accelerometers to accurately assess daily PA.

\section{Research Methods and Procedures}

The PubMed Central database (U.S. NIH free digital archive of biomedical and life sciences journal literature) was searched using the following key words: doubly or double labeled or labeled water in combination with accelerometer, accelerometry, motion sensor, or activity monitor. In total, 41 articles were identified, and screening the articles' references resulted in one extra article. One article was excluded because it was written in French (40), and 13 more articles were excluded because they contained no data about accelerometry or DLW, contained no new data, or the primary aim was not to compare both methods and, hence, no correlations or mean differences between methods were provided $(19,41-52)$.

\section{Results}

Eight different accelerometers were identified, three uniaxial, one biaxial, two triaxial, a device based on two position sensors and two motion sensors (ActiReg), and a foot-ground contact pedometer. The Lifecorder (Suzuken Co., Japan $)$ is a uniaxial accelerometer $(62 \times 46 \times 26 \mathrm{~mm}$; $42 \mathrm{~g})$ detecting accelerations along the vertical axis. Before use, the accelerometer is programmed with age, gender, height, and body weight, and PA is expressed as the energy spent on activity in kilocalories (53). The Actigraph/CSA/ MTI (first known as CSA, Computer Science Applications model 7164; later known as MTI, Manufacturing Technology Inc., Fort Walton Beach, FL; now known as Actigraph, Health One Technology, Fort Walton Beach, FL) is a small, lightweight, uniaxial accelerometer detecting accelerations from 0.05 to $2 \mathrm{~g}$ (54). The Caltrac (Muscle Dynamics Fitness network, Torrance, CA) is a uniaxial accelerometer that has a ceramic piezo-electric transducer that detects vertical displacement. The signal is translated into a total activity energy count per day (55). The Actiwatch AW16 (Minimitter Co., Inc.) is a small $(28 \times 27 \times 10 \mathrm{~mm})$, lightweight (16 g), biaxial accelerometer (56). Activity is measured by means of a piezo-electric accelerometer that is set up to record the integration of intensity, amount, and duration of movement (56). The Tritrac-R3D (Professional Products, Madison, WI) is a triaxial accelerometer providing minute-by-minute activity counts for the anteroposterior $(\mathrm{X})$, mediolateral $(\mathrm{Y})$, and vertical $(\mathrm{Z})$ direction, as well as the vector magnitude calculated as $\mathrm{V}\left(\mathrm{X}^{2}+\mathrm{Y}^{2}+\mathrm{Z}^{2}\right)$ (57). The Tracmor (Philips Research, Eindhoven, The Netherlands) is a triaxial accelerometer containing three uniaxial piezo-electric accelerometers. It measures $72 \times 26 \times 7 \mathrm{~mm}$ and weighs $22 \mathrm{~g}$ (battery included). Accelerometer output (counts) represents the rectified and integrated acceleration signal, stored minute by minute for each axis, $\mathrm{X}$ (mediolateral), Y (longitudinal or vertical), and Z (anteroposterior), separately (58). The Tracmor is not yet commercially available. The ActiReg (PreMed AS, Oslo, Norway) has two body position sensors (tilt switches) and two motion sensors connected by cables to a battery-operated storage unit $(85 \times$ $45 \times 15 \mathrm{~mm}, 60 \mathrm{~g}$ ) that is fixed to an elastic belt worn around the waist. Energy expenditure is calculated from the identification of different body positions and motions multiplied by literature values for the energy costs of different activities (59). The foot-ground contact pedometer (Fitsense Technology Inc., Southboro, MA) is a small electronic device $(\sim 5.8 \mathrm{~cm} \times 7.6 \mathrm{~cm} \times 6.4 \mathrm{~cm} ; 56 \mathrm{~g})$ that fits into a cloth pouch mounted to the outside of the boot or shoe through the shoelaces. The monitor measures the footground contact time and classifies activities as run, walk, non-exercise activity, or no activity by the pattern of the foot-ground contact waveforms (60).

Table 1 summarizes the results of all of the identified studies. For every study, the dependent and independent variables are given, as well as correlations and partial correlations when provided. Some studies only mentioned mean differences between DLW-derived EE and calculated EE based on the activity monitor and subjects' characteristics. For two studies, the increase in $\mathrm{R}$ caused by the activity counts is mentioned.

\section{Discussion}

The advantage of accelerometry is that it can provide information about the total amount, the frequency, the intensity, and the duration of PA in daily life. The advantage of DLW is that it is the only technique available to accurately measure EE in daily life over longer periods of time. Ideally, the combination of both methods should be used to gain further insight into the level of PA. However, given the 


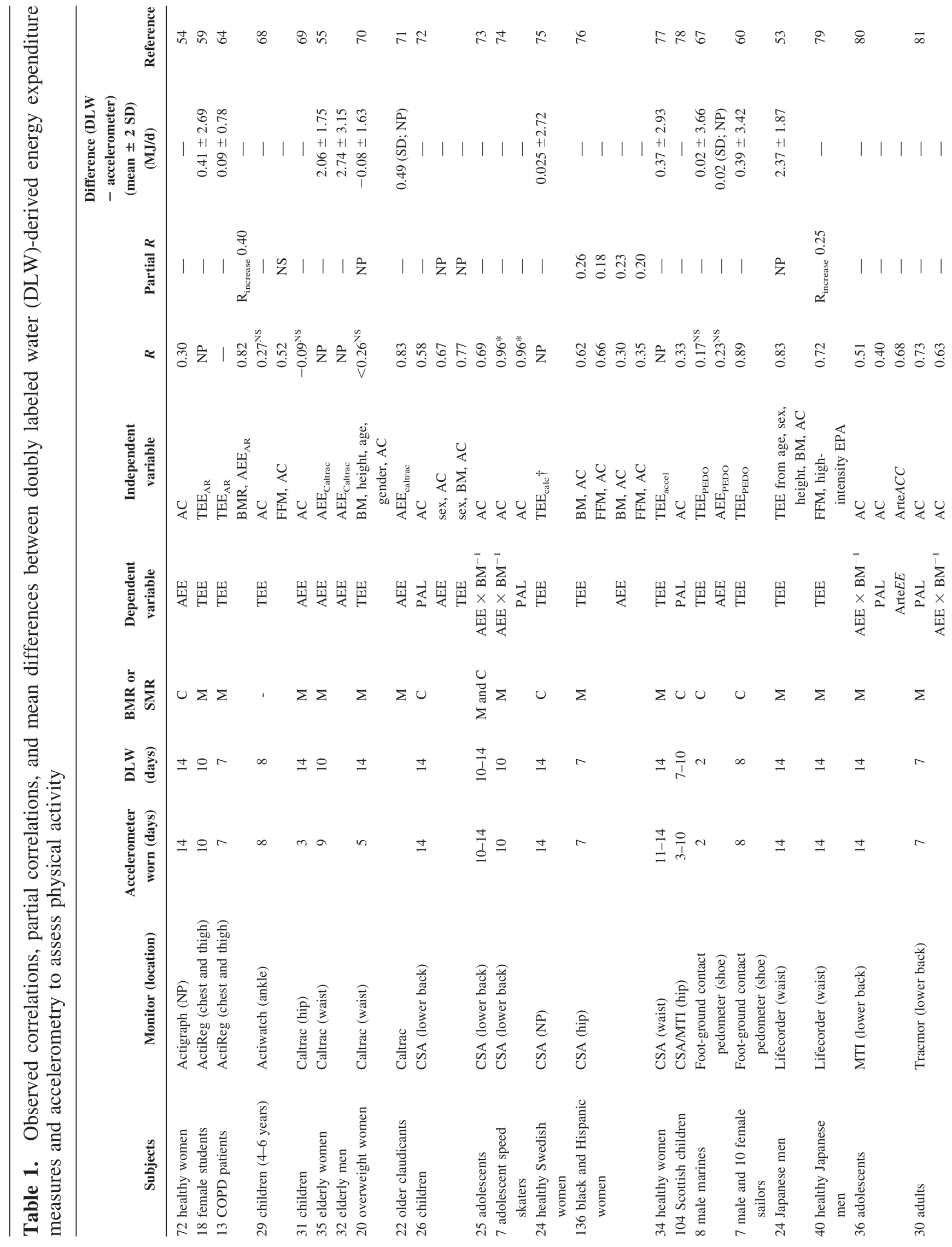




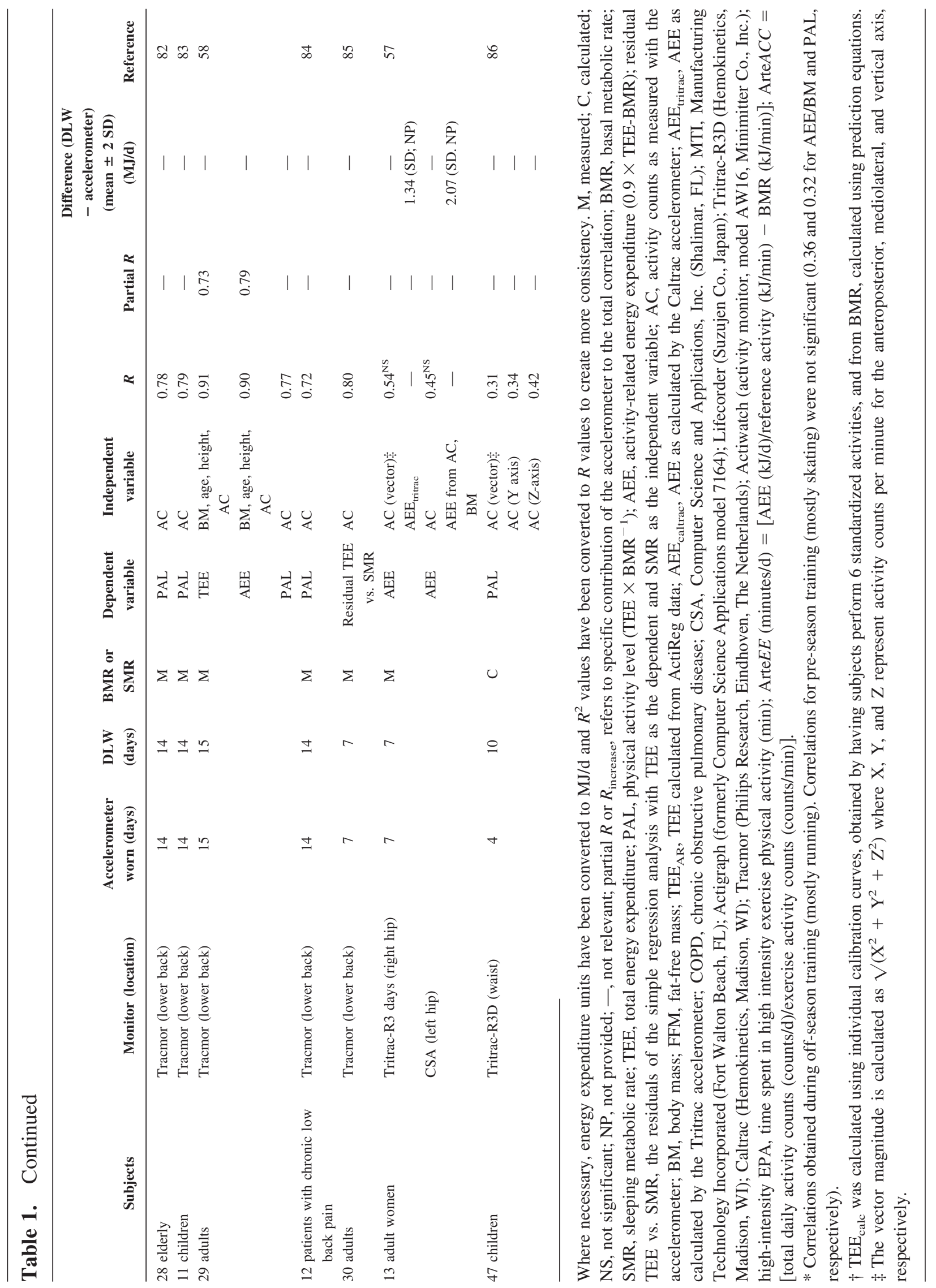


high cost of DLW, the combination of DLW with accelerometry is not always possible and is rarely used for large study populations. Many studies, therefore, have been aimed at developing prediction equations, based on accelerometry and subject characteristics, to predict DLW-derived EE measures. When comparing the validity of different accelerometers, some considerations should be made. First, when multiple regression is used with subject characteristics and activity counts, many studies do not mention partial correlations for activity counts or the increase in $R^{2}$ caused by the activity counts. For example, in the study of Rafamantanantsoa et al. (53), the accelerometer predicted TEE of $69 \%$ ( $R=0.83$, Table 1$)$, while the calculation of TEE from the accelerometer was based on age, sex, height, body mass (BM), and activity counts and no data on the contribution of the activity counts were available. Studies using the Caltrac have the same shortcoming and should, therefore, be interpreted with care. A validation study of the Caltrac using a respiration chamber showed that Caltracestimated EE was, and Caltrac counts only were not, correlated with chamber-assessed EE, $r=0.81$ to 0.87 ( $p<$ $0.001)$ and $r=0.11$ to 0.14 (not significant), respectively (61). In comparison, in the study of Plasqui et al. (58), age, $\mathrm{BM}$, and height alone already explained 64\%, and the accelerometer (Tracmor) added 19\% of the variation in TEE. Second, some studies only present the mean difference between methods after EE has been calculated using subject characteristics and accelerometer output. Again, there is no information available about whether or not the accelerometer output significantly contributed to the prediction equation. Third, to have some idea about the ability of the accelerometer to predict individual EE rather than EE on a group level only, standard errors (when using regression analysis) or limits of agreement (when using mean differences) should be presented. Fourth, various methods can be applied to correct EE for body size and composition. The simplest method is the use of ratios such as the PAL $\left(\mathrm{TEE} \times \mathrm{BMR}^{-1}\right)$. Theoretically, the use of ratios is justified only when the regression line of the numerator vs. the denominator has a zero intercept. If not, the impact of a non-zero intercept is bigger at the lower range of EE. The same problem occurs when trying to correct AEE for BM or body composition. Many authors use $\mathrm{AEE} \times \mathrm{BM}^{-1}$ as a measure of PA. Prentice et al. (62) suggested using BM to the exponent of 0.5 rather than 1 as the denominator, since not all activities have the same weight-bearing impact on AEE. But they also emphasize that it is not recommended to use this as a universal approach and that there is probably no generally applicable adjustment factor. On the other hand, Schoeller et al. concluded that dividing AEE by body weight is an appropriate means of comparing the volume of PA among individuals of different body size (63). They correlated AEE, as measured during strictly standardized light activities, with BM, fat free mass (FFM), fat mass
(FM), and resting metabolic rate (RMR) and found the best correlations, as well as a zero intercept, for BM. This is perhaps not surprising because 1) when AEE is used as the dependent variable, RMR is already removed from TEE; and 2) FFM is the major determinant of RMR, but once PA is performed, the effect of FM in addition to that of FFM becomes larger since FM can then be considered as extra weight to be moved. As BM includes both FFM and FM, $\mathrm{BM}$ was found to be a better predictor of AEE then either of the components separately. Multiple regression with both FFM and FM, however, might have resulted in an even better correlation, since both contribute to AEE to a different extent (58). Therefore, the use of regression analysis is probably the most appropriate approach. Both BM and gender or, when data on body composition are available, both FM and FFM can be entered as independent variables. Finally, methodological differences in the study designs could affect the outcomes. The location of the monitor on the body varies. The observation period of the accelerometer and DLW should always coincide. There might also be differences in the standard operating procedure for DLW among laboratories. Basal or sleeping metabolic rate can be measured or calculated. The level of PA, as well as the range in PALs, differ among populations and can influence the results. For example, in the study of Arvidsson et al., the EE assessed using the ActiReg shows good agreement with DLW, but the authors correctly conclude that this applies to a population with a low PAL (i.e., patients with chronic obstructive pulmonary disease, average PAL 1.51) (64). Another study with the ActiReg in female students with higher PALs (average PAL 1.71) showed much poorer results (59). All of these factors complicate the comparison among studies and different accelerometers and should be taken into account when interpreting the results presented in Table 1.

Of the uniaxial accelerometers, the Actigraph or CSA/ MTI is the only commercially available accelerometer that has repeatedly been shown to significantly correlate with DLW-derived EE. Actiwatch counts did not significantly correlate with TEE. None of the studies using the Caltrac showed good correlations for activity counts and EE, and high mean differences were reported between measured and calculated EE. No partial correlations for activity counts were mentioned for the Lifecorder, but one study showed a significant increase in $R$ when time spent in high-intensity exercise, as determined by the accelerometer, was used. The Tritrac-R3D did not correlate with AEE in a small sample of 13 women, but the lack of significance might be due to the small sample size and the fact that no correction for body size was made. Another study, using the Tritrac-R3D in a group of children, showed significant correlations between PAL and activity counts when either the total vector, the Y-axis, or the Z-axis was used. The only other triaxial accelerometer validated is the Tracmor. Correlations be- 
tween activity counts and EE for various versions of this accelerometer range between 0.63 and 0.80 .

Ideally, prediction equations should also be validated in a cross-validation group. Because of the low number of subjects in most studies, however, a problem inherent to the use of DLW, this is usually not possible.

Recently, devices other than standard accelerometers have been developed, such as the ActiReg (59) and the Intelligent Device for Energy Expenditure and Activity $(65,66)$, that use multiple sensors to assess both body posture and body movement, which are then translated into EE. The ActiReg-calculated TEE did not significantly differ from DLW-measured TEE on a group level, but the individual variation in the difference between both methods was large. Furthermore, the ActiReg underestimated TEE to a greater extent at higher levels of EE (>11 MJ/d) (59). The Intelligent Device for Energy Expenditure and Activity showed good results under laboratory conditions but has not been validated against DLW. These devices require multiple sensors to be attached to the body and have a relatively large data acquisition unit, thereby diminishing wearing comfort. So far, they have not been proven to be superior in the estimation of EE to simpler accelerometers, and further research is required to determine their effectiveness as a measure of daily life EE. The foot-ground contact pedometer is also accelerometry-based but uses a different approach than standard accelerometers. It derives TEE from calculated BMR and the metabolic cost of locomotion, calculated from the foot-ground contact time and total subject weight (body weight + load) $(60,67)$. The mean difference between the monitor and DLW was fairly low, but the limits of agreement were large.

In summary, from Table 1 it is clear that the CSA/MTI and the Tracmor are the two most extensively validated accelerometers. The best results were found for the Tracmor; however, this accelerometer is not yet commercially available. Of those commercially available, only the CSA/ MTI has been proven to correlate reasonably with DLWderived EE. Future validation studies might consider the issues mentioned in the discussion as a guideline and provide as much information as possible on the actual contribution of the accelerometer counts to the prediction of EE.

\section{Acknowledgments}

There was no funding/outside support for this study.

\section{References}

1. Riddoch CJ, Bo Andersen L, Wedderkopp N, et al. Physical activity levels and patterns of 9- and 15-yr-old European children. Med Sci Sports Exerc. 2004;36:86-92.

2. Seefeldt V, Malina RM, Clark MA. Factors affecting levels of physical activity in adults. Sports Med. 2002;32:143-68.

3. Panagiotakos DB, Chrysohoou C, Pitsavos C, et al. Risk factors of stroke mortality: a 40-year follow-up of the Corfu cohort from the Seven-Countries Study. Neuroepidemiology. 2003;22:332-8.
4. Fang J, Wylie-Rosett J, Cohen HW, Kaplan RC, Alderman MH. Exercise, body mass index, caloric intake, and cardiovascular mortality. Am J Prev Med. 2003;25:283-9.

5. Mensink M, Feskens EJ, Saris WH, De Bruin TW, Blaak EE. Study on Lifestyle Intervention and Impaired Glucose Tolerance Maastricht (SLIM): preliminary results after one year. Int J Obes. 2003;27:377-84.

6. Kriska AM, Saremi A, Hanson RL, et al. Physical activity, obesity, and the incidence of type 2 diabetes in a high-risk population. Am J Epidemiol. 2003;158:669-75.

7. Hu G, Qiao Q, Silventoinen K, et al. Occupational, commuting, and leisure-time physical activity in relation to risk for Type 2 diabetes in middle-aged Finnish men and women. Diabetologia. 2003;46:322-9.

8. Hu FB, Li TY, Colditz GA, Willett WC, Manson JE. Television watching and other sedentary behaviors in relation to risk of obesity and type 2 diabetes mellitus in women. JAMA. 2003;289:1785-91.

9. Neville CE, Murray LJ, Boreham CA, et al. Relationship between physical activity and bone mineral status in young adults: the Northern Ireland Young Hearts Project. Bone. 2002;30:792-8.

10. Kai MC, Anderson M, Lau EM. Exercise interventions: defusing the world's osteoporosis time bomb. Bull World Health Organ. 2003;81:827-30.

11. Williams PT. Vigorous exercise and the population distribution of body weight. Int J Obes Relat Metab Disord. 2004;28: 120-8.

12. Weinsier RL, Hunter GR, Desmond RA, Byrne NM, Zuckerman PA, Darnell BE. Free-living activity energy expenditure in women successful and unsuccessful at maintaining a normal body weight. Am J Clin Nutr. 2002;75:499-504.

13. Jebb SA, Moore MS. Contribution of a sedentary lifestyle and inactivity to the etiology of overweight and obesity: current evidence and research issues. Med Sci Sports Exerc. 1999;31(11 Suppl):S534-41.

14. Gotay CC. Behavior and cancer prevention. J Clin Oncol. 2005;23:301-10.

15. Visscher TL, Kromhout D, Seidell JC. Long-term and recent time trends in the prevalence of obesity among Dutch men and women. Int J Obes Relat Metab Disord. 2002;26: 1218-24.

16. Ogden CL, Flegal KM, Carroll MD, Johnson CL. Prevalence and trends in overweight among US children and adolescents, 1999-2000. JAMA. 2002;288:1728-32.

17. Flegal KM, Carroll MD, Ogden CL, Johnson CL. Prevalence and trends in obesity among US adults, 1999-2000. JAMA. 2002;288:1723-7.

18. Caspersen CJ, Powell KE, Christenson GM. Physical activity, exercise, and physical fitness: definitions and distinctions for health-related research. Public Health Rep. 1985;100: 126-31.

19. Westerterp KR. Assessment of physical activity level in relation to obesity: current evidence and research issues. Med Sci Sports Exerc. 1999;31(11 Suppl):S522-5.

20. Schutz Y, Weinsier RL, Hunter GR. Assessment of freeliving physical activity in humans: an overview of currently available and proposed new measures. Obes Res. 2001;9:36879. 
21. Lamonte MJ, Ainsworth BE. Quantifying energy expenditure and physical activity in the context of dose response. Med Sci Sports Exerc. 2001;33(Suppl 6):S370-8; discussion S419-20.

22. Montoye HJ, Kemper HCG, Saris WHM, Washburn RA. Measuring Physical Activity and Energy Expenditure. Champaign, IL: Human Kinetics; 1996, p. 191.

23. Schulman JL, Reisman JM. An objective measure of hyperactivity. Am J Ment Defic. 1959;64:455-6.

24. Melanson EL Jr, Freedson PS. Physical activity assessment: a review of methods. Crit Rev Food Sci Nutr. 1996;36:38596.

25. LaPorte RE, Kuller LH, Kupfer DJ, McPartland RJ, Matthews G, Caspersen C. An objective measure of physical activity for epidemiologic research. Am J Epidemiol. 1979; 109:158-68.

26. Schneider PL, Crouter SE, Bassett DR. Pedometer measures of free-living physical activity: comparison of 13 models. Med Sci Sports Exerc. 2004;36:331-5.

27. Bassett DR Jr. Validity and reliability issues in objective monitoring of physical activity. Res Q Exerc Sport. 2000; 71(Suppl 2):30-6.

28. Bouten CV, Koekkoek KT, Verduin M, Kodde R, Janssen JD. A triaxial accelerometer and portable data processing unit for the assessment of daily physical activity. IEEE Trans Biomed Eng. 1997;44:136-47.

29. Bouten CV, Westerterp KR, Verduin M, Janssen JD. Assessment of energy expenditure for physical activity using a triaxial accelerometer. Med Sci Sports Exerc. 1994;26:151623.

30. Terrier P, Aminian K, Schutz Y. Can accelerometry accurately predict the energy cost of uphill/downhill walking? Ergonomics. 2001;44:48-62.

31. Montoye HJ, Washburn R, Servais S, Ertl A, Webster JG, Nagle FJ. Estimation of energy expenditure by a portable accelerometer. Med Sci Sports Exerc. 1983;15:403-7.

32. Nichols JF, Morgan CG, Sarkin JA, Sallis JF, Calfas KJ. Validity, reliability, and calibration of the Tritrac accelerometer as a measure of physical activity. Med Sci Sports Exerc. 1999;31:908-12.

33. Nichols JF, Morgan CG, Chabot LE, Sallis JF, Calfas KJ. Assessment of physical activity with the Computer Science and Applications, Inc., accelerometer: laboratory versus field validation. Res $Q$ Exerc Sport. 2000;71:36-43.

34. Levine JA, Baukol PA, Westerterp KR. Validation of the Tracmor triaxial accelerometer system for walking. Med Sci Sports Exerc. 2001;33:1593-7.

35. Hendelman D, Miller K, Baggett C, Debold E, Freedson P. Validity of accelerometry for the assessment of moderate intensity physical activity in the field. Med Sci Sports Exerc. 2000;32(Suppl 9):442-9.

36. Bassett DR Jr, Ainsworth BE, Swartz AM, Strath SJ, O'Brien WL, King GA. Validity of four motion sensors in measuring moderate intensity physical activity. Med Sci Sports Exerc. 2000;32(Suppl 9):471-80.

37. Puyau MR, Adolph AL, Vohra FA, Butte NF. Validation and calibration of physical activity monitors in children. Obes Res. 2002;10:150-7.
38. Kumahara H, Schutz Y, Ayabe M, et al. The use of uniaxial accelerometry for the assessment of physical-activity-related energy expenditure: a validation study against whole-body indirect calorimetry. Br J Nutr. 2004;91:235-43.

39. Avons P, Garthwaite P, Davies HL, Murgatroyd PR, James WP. Approaches to estimating physical activity in the community: calorimetric validation of actometers and heart rate monitoring. Eur J Clin Nutr. 1988;42:185-96.

40. Gottrand F. Measurement of energy expenditure of children in habitual living conditions. Arch Pediatr. 1998;5:1020-2.

41. Reilly JJ, Jackson DM, Montgomery C, et al. Total energy expenditure and physical activity in young Scottish children: mixed longitudinal study. Lancet. 2004;363:211-2.

42. Meijer GA, Westerterp KR, van Hulsel AM, ten Hoor F. Physical activity and energy expenditure in lean and obese adult human subjects. Eur J Appl Physiol Occup Physiol. 1992;65:525-8.

43. Van Etten LM, Westerterp KR, Verstappen FT, Boon BJ, Saris WH. Effect of an 18-wk weight-training program on energy expenditure and physical activity. J Appl Physiol. 1997;82:298-304.

44. Gottlieb SS, Fisher ML, Freudenberger R, et al. Effects of exercise training on peak performance and quality of life in congestive heart failure patients. J Card Fail. 1999;5:188-94.

45. Skotzko CE, Krichten C, Zietowski G, et al. Depression is common and precludes accurate assessment of functional status in elderly patients with congestive heart failure. J Card Fail. 2000;6:300-5.

46. Westerterp KR, Plasqui G. Physical activity and human energy expenditure. Curr Opin Clin Nutr Metab Care. 2004; 7:607-13.

47. Westerterp KR. Physical activity assessment with accelerometers. Int J Obes Relat Metab Disord. 1999;23(Suppl 3): 45-9.

48. Ekelund U, Aman J, Yngve A, Renman C, Westerterp K, Sjöström M. Physical activity but not energy expenditure is reduced in obese adolescents: a case-control study. Am J Clin Nutr. 2002;76:935-41.

49. Beghin L, Budniok T, Vaksman G, et al. Simplification of the method of assessing daily and nightly energy expenditure in children, using heart rate monitoring calibrated against open circuit indirect calorimetry. Clin Nutr. 2000;19:425-35.

50. Heil DP. Estimating energy expenditure in wildland fire fighters using a physical activity monitor. Appl Ergon. 2002;33: 405-13.

51. Treuth MS, Butte NF, Puyau M, Adolph A. Relations of parental obesity status to physical activity and fitness of prepubertal girls. Pediatrics. 2000;106:E49.

52. Goris AH, Meijer EP, Kester A, Westerterp KR. Use of a triaxial accelerometer to validate reported food intakes. Am J Clin Nutr. 2001;73:549-53.

53. Rafamantanantsoa HH, Ebine N, Yoshioka M, et al. Validation of three alternative methods to measure total energy expenditure against the doubly labeled water method for older Japanese men. J Nutr Sci Vitaminol (Tokyo). 2002;48:517-23.

54. Adams SA, Matthews CE, Ebbeling CB, et al. The effect of social desirability and social approval on self-reports of physical activity. Am J Epidemiol. 2005;161:389-98. 
55. Starling RD, Matthews DE, Ades PA, Poehlman ET. Assessment of physical activity in older individuals: a doubly labeled water study. J Appl Physiol. 1999;86:2090-6.

56. Minimitter Company. AW-16 \& AW-64 Actigraph Specifications. http://www.minimitter.com/Products/Actiwatch/ (Accessed 2006).

57. Leenders NY, Sherman WM, Nagaraja HN, Kien CL. Evaluation of methods to assess physical activity in free-living conditions. Med Sci Sports Exerc. 2001;33:1233-40.

58. Plasqui G, Joosen AM, Kester AD, Goris AH, Westerterp KR. Measuring free-living energy expenditure and physical activity with triaxial accelerometry. Obes Res. 2005;13: 1363-9.

59. Hustvedt BE, Christophersen A, Johnsen LR, et al. Description and validation of the ActiReg: a novel instrument to measure physical activity and energy expenditure. $\mathrm{Br} J$ Nutr. 2004;92:1001-8.

60. Tharion WJ, Yokota M, Buller MJ, DeLany JP, Hoyt RW. Total energy expenditure estimated using a foot-contact pedometer. Med Sci Monit. 2004;10:CR504-9.

61. Bray MS, Wong WW, Morrow JR Jr, Butte NF, Pivarnik JM. Caltrac versus calorimeter determination of 24-h energy expenditure in female children and adolescents. Med Sci Sports Exerc. 1994;26:1524-30.

62. Prentice AM, Goldberg GR, Murgatroyd PR, Cole TJ. Physical activity and obesity: problems in correcting expenditure for body size. Int J Obes Relat Metab Disord. 1996;20: 688-91.

63. Schoeller DA, Jefford G. Determinants of the energy costs of light activities: inferences for interpreting doubly labeled water data. Int J Obes Relat Metab Disord. 2002;26:97-101.

64. Arvidsson D, Slinde F, Nordenson A, Larsson S, Hulthen L. Validity of the ActiReg system in assessing energy requirement in chronic obstructive pulmonary disease patients. Clin Nutr. 2006;25:68-74.

65. Zhang K, Pi-Sunyer FX, Boozer CN. Improving energy expenditure estimation for physical activity. Med Sci Sports Exerc. 2004;36:883-9.

66. Zhang K, Werner P, Sun M, Pi-Sunyer FX, Boozer CN. Measurement of human daily physical activity. Obes Res. 2003;11:33-40.

67. Hoyt RW, Buller MJ, Santee WR, Yokota M, Weyand PG, Delany JP. Total energy expenditure estimated using footground contact pedometry. Diabetes Technol Ther. 2004;6: $71-81$.

68. Lopez-Alarcon M, Merrifield J, Fields DA, et al. Ability of the actiwatch accelerometer to predict free-living energy expenditure in young children. Obes Res. 2004;12:185965.

69. Johnson RK, Russ J, Goran MI. Physical activity related energy expenditure in children by doubly labeled water as compared with the Caltrac accelerometer. Int J Obes Relat Metab Disord. 1998;22:1046-52.

70. Fogelholm M, Hiilloskorpi H, Laukkanen R, Oja P, Van Marken Lichtenbelt W, Westerterp K. Assessment of energy expenditure in overweight women. Med Sci Sports Exerc. 1998;30:1191-7.

71. Gardner AW, Poehlman ET. Assessment of free-living daily physical activity in older claudicants: validation against the doubly labeled water technique. J Gerontol A Biol Sci Med Sci. 1998;53:M275-80.

72. Ekelund U, Sjöström M, Yngve A, et al. Physical activity assessed by activity monitor and doubly labeled water in children. Med Sci Sports Exerc. 2001;33:275-81.

73. Ekelund U, Yngve A, Brage S, Westerterp K, Sjöström M. Body movement and physical activity energy expenditure in children and adolescents: how to adjust for differences in body size and age. Am J Clin Nutr. 2004;79:851-6.

74. Ekelund U, Yngve A, Sjöström M, Westerterp K. Field evaluation of the Computer Science and Application's Inc. activity monitor during running and skating training in adolescent athletes. Int J Sports Med. 2000;21:586-92.

75. Lof M, Hannestad U, Forsum E. Assessing physical activity of women of childbearing age: ongoing work to develop and evaluate simple methods. Food Nutr Bull. 2002;23(Suppl 3): 30-3.

76. Masse LC, Fulton JE, Watson KL, Mahar MT, Meyers MC, Wong WW. Influence of body composition on physical activity validation studies using doubly labeled water. $J$ Appl Physiol. 2004;96:1357-64.

77. Lof M, Hannestad U, Forsum E. Comparison of commonly used procedures, including the doubly-labelled water technique, in the estimation of total energy expenditure of women with special reference to the significance of body fatness. $\mathrm{Br} J$ Nutr. 2003;90:961-8.

78. Montgomery C, Reilly JJ, Jackson DM, et al. Relation between physical activity and energy expenditure in a representative sample of young children. Am J Clin Nutr. 2004;80: 591-6.

79. Rafamantanantsoa HH, Ebine N, Yoshioka M, et al. The role of exercise physical activity in varying the total energy expenditure in healthy Japanese men 30 to 69 years of age. $J$ Nutr Sci Vitaminol (Tokyo). 2003;49:120-4.

80. Ekelund U, Aman J, Westerterp K. Is the ArteACC index a valid indicator of free-living physical activity in adolescents? Obes Res. 2003;11:793-801.

81. Bouten CV, Verboeket-van de Venne WP, Westerterp KR, Verduin M, Janssen JD. Daily physical activity assessment: comparison between movement registration and doubly labeled water. J Appl Physiol. 1996;81:1019-26.

82. Meijer EP, Goris AH, Wouters L, Westerterp KR. Physical inactivity as a determinant of the physical activity level in the elderly. Int J Obes Relat Metab Disord. 2001;25:935-9.

83. Hoos MB, Plasqui G, Gerver WJ, Westerterp KR. Physical activity level measured by doubly labeled water and accelerometry in children. Eur J Appl Physiol. 2003;89:624-6.

84. Verbunt JA, Westerterp KR, van der Heijden GJ, Seelen HA, Vlaeyen JW, Knottnerus JA. Physical activity in daily life in patients with chronic low back pain. Arch Phys Med Rehabil. 2001;82:726-30.

85. Westerterp KR, Bouten CV. Physical activity assessment: comparison between movement registration and doubly labeled water method. Z Ernahrungswiss. 1997;36:263-7.

86. Abbott RA, Davies PS. Habitual physical activity and physical activity intensity: their relation to body composition in 5.0-10.5-y-old children. Eur J Clin Nutr. 2004;58:285-91. 